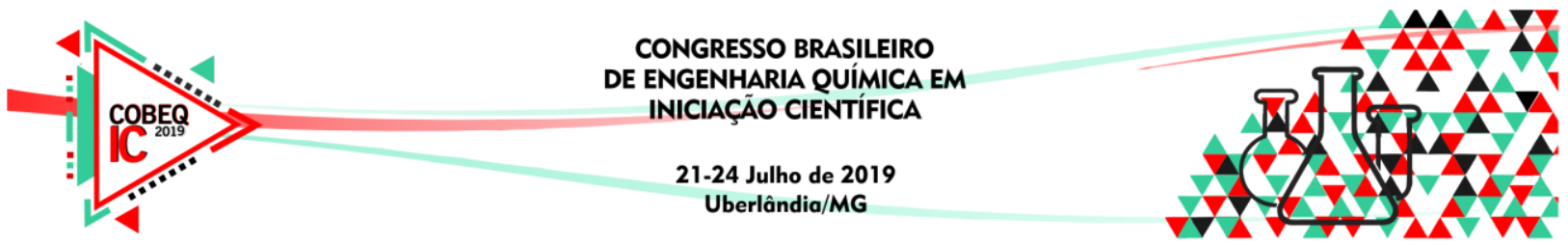

\title{
EFEITO DA ENERGIA DE SOLDAGEM NA RESISTÊNCIA À CORROSÃO DO AÇO AUSTENÍTICO 316L, EM MEIO SALINO
}

\author{
A. L. G. EURIDES ${ }^{1}$, M. M. A. M. SCHVARTZMAN ${ }^{1}$ \\ ${ }^{1}$ Pontifícia Universidade Católica de Minas Gerais, Departamento de Engenharia Química \\ E-mail para contato: analuiza.eurides@ hotmail.com
}

\begin{abstract}
RESUMO - O aço inoxidável austenítico 316L é largamente utilizado em diversas aplicações industriais, devido a formação de uma camada protetora à corrosão. Os processos de soldagem mais utilizados para aços inoxidáveis podem se tornar inviáveis caso as chapas a serem soldadas possuam média e alta espessura, devido ao número de passes necessários e ao alto gasto de tempo. A soldagem por arco submerso pode superar tais limitações, devido ao menor número de passes e a maior taxa de deposição de material comparativamente a outros processos. Contudo, solda em chapas espessas, pode acarretar em altas taxas de transferência de calor, as quais podem afetar a microestrutura do material, suas características mecânicas e suas propriedades frente à corrosão. Neste trabalho foi estudada a influência da energia de soldagem a arco submerso na corrosão por pite do aço inoxidável austenítico 316L, em meio salino. Foram utilizados dois valores de energias de soldagem 2,61 e 4,35 kJ/mm. Para o estudo da corrosão foram realizados ensaios eletroquímicos no potenciostato.
\end{abstract}

\section{INTRODUÇÃO}

Os aços inoxidáveis austeníticos (AIA) são não magnéticos, não endurecíveis e quando sofrem o processo de encruamento, o aumento da dureza é bem superior ao que se encontraria mediante à mesma deformação, em outros aços. A ampla utilização destes, deve-se a uma combinação favorável de suas propriedades, tais como, resistência à corrosão e à oxidação, resistência mecânica a quente, trabalhabilidade e soldabilidade. Não é somente a matriz austenítica que determina as propriedades destes materiais. Diversas fases, tais como ferrita $\delta$, carbonetos, fases intermetálicas, nitretos, sulfetos, dentre outras, podem estar presentes na microestrutura dos aços inoxidáveis austeníticos. Estudos mostram que a quantidade, o tamanho, a distribuição e a forma destas fases têm influência marcante nas propriedades desse material. (PADILHA, 1994).

O processo de corrosão por pites é de natureza eletroquímica, pois a pequena região exposta funciona como anodo, a região protegida funciona como catodo e o meio corrosivo como um eletrólito. Este tipo de corrosão é muito característica dos materiais metálicos passiváveis, isto é, formadores de película protetora. Nos pontos de rompimento da camada passiva, forma-se uma pilha, ativa passiva, resultando na formação destas cavidades. Ela é de difícil acompanhamento e controle, pois a perda de massa e de espessura do material não é expressiva, o que dificulta a observação do desgaste ocorrido (NUNES, 2007). 


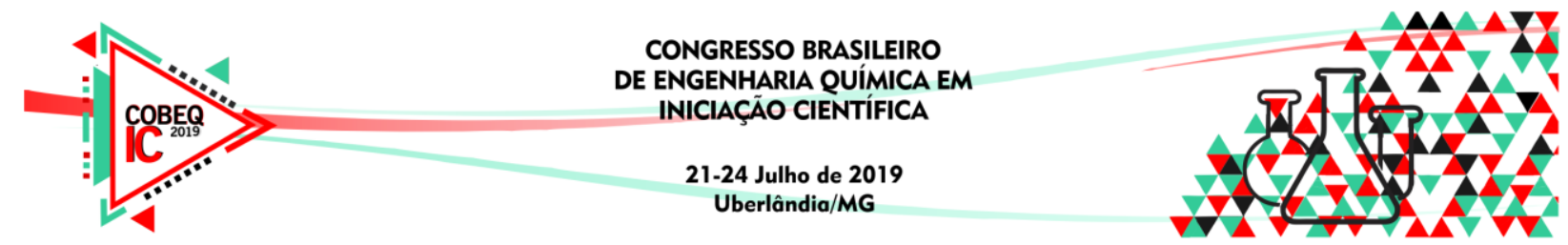

A soldagem é um processo de união entre duas partes metálicas, utilizando fonte de calor, com ou sem aplicação de pressão, com ou sem material de adição (WAINER et al., 2004). O arco elétrico é a fonte de calor mais utilizada na soldagem por fusão de materiais metálicos, pois apresenta uma combinação ótima de características, incluindo uma concentração adequada de energia para a fusão localizada do metal base, facilidade de controle e baixo custo relativo ao equipamento (MARQUES et al., 2009).

O objetivo deste trabalho é estudar a característica à corrosão do aço inoxidável $316 \mathrm{~L}$ ao ser submetido ao processo de soldagem por arco submerso. Para tal estudo, uma chapa de aço 316L foi soldada, utilizando dois valores de energia de soldagem, e foram realizados ensaios eletroquímicos para avaliar a resistência à corrosão dos corpos de prova.

\section{METODOLOGIA}

Utilizou-se amostras de aço inoxidável austenítico AISI 316L com dimensões de $100 \mathrm{x}$ $150 \mathrm{~mm}$ e espessura de $20 \mathrm{~mm}$. A composição química deste material foi obtida pela técnica de espectrometria óptica no Laboratório de Ensaios e Análises em Materiais - LAMAT do SENAI - FIEMG, sendo descrita na Tabela 1. A partir da composição química, pode-se observar o baixo teor de carbono e a presença de $\mathrm{Cr}$ e Mo, componentes importantes na resistência à corrosão do aço.

Tabela 1 - Composição química (\% peso) do aço inoxidável austenítico - AISI 316L.

\begin{tabular}{|c|c|c|c|c|c|c|c|c|}
\hline $\mathrm{C}$ & $\mathrm{Mn}$ & $\mathrm{P}$ & $\mathrm{S}$ & $\mathrm{Si}$ & $\mathrm{Ni}$ & $\mathrm{Cr}$ & $\mathrm{Mo}$ & $\mathrm{Al}$ \\
\hline 0,0101 & 1,3106 & 0,0299 & 0,0028 & 0,4596 & 9,8952 & 16,7628 & 2,0486 & 0,0024 \\
\hline
\end{tabular}

Foi utilizado um arame tubular, com diâmetro de 2,4 mm. A composição química do arame é apresentada na Tabela 2. A escolha do arame se deu, principalmente, pela sua composição, que se aproxima da composição do aço, evitando problemas de alteração de resistência mecânica do aço, por exemplo.

Tabela 2 - Composição Química do arame sólido (\% peso)

\begin{tabular}{|c|c|c|c|c|c|}
\hline $\mathrm{C}$ & $\mathrm{Mn}$ & $\mathrm{Mo}$ & $\mathrm{Si}$ & $\mathrm{Ni}$ & $\mathrm{Cr}$ \\
\hline$<0,03$ & 1,8 & 2,80 & 0,50 & 12,50 & 19,0 \\
\hline
\end{tabular}

Empregando-se o processo de soldagem a arco submerso, foram feitos cordões sobre chapa, utilizando dois valores de energia de soldagem. A velocidade, a tensão e o rendimento foram fixados em $30 \mathrm{~cm} . \mathrm{s}^{-1}, 29 \mathrm{~V}$ e 0,9 , respectivamente. Na primeira amostra, a corrente utilizada foi de $300 \mathrm{~A}$, obtendo-se energia de $2,61 \mathrm{kJmm}^{-1}$, e na segunda amostra, foi utilizada corrente de 500 A, obtendo-se energia de $4,35 \mathrm{~kJ} . \mathrm{mm}^{-1}$. Os valores de energia foram calculados a partir da Equação 1, 


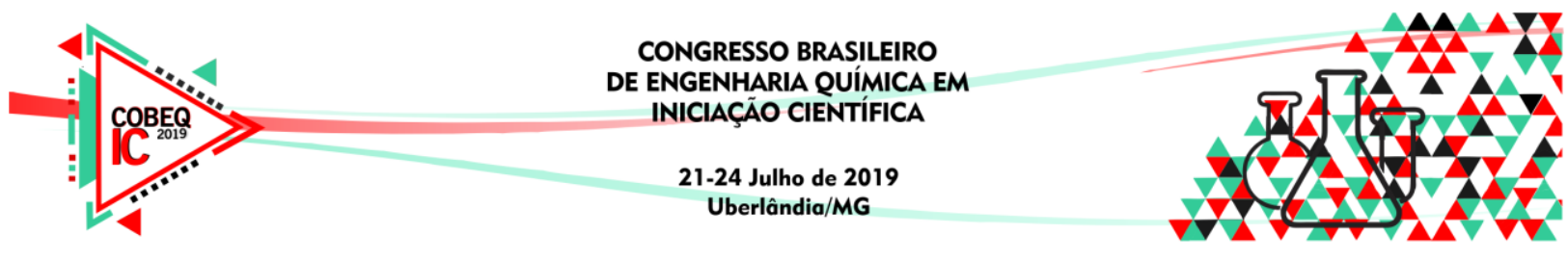

$H=\frac{\eta x V x I}{v}$

Sendo $\mathrm{H}$ a energia, em $\mathrm{kj} / \mathrm{cm}, \eta$, o rendimento térmico, $\mathrm{V}$, a tensão do arco, em volts, $\mathrm{I}$, a corrente, em amperes, e v, a velocidade, em $\mathrm{cm} / \mathrm{s}$.

\section{Análise da microestrutura}

A fim de se analisar a microestrutura das soldas, as amostras foram cortadas transversalmente ao cordão sobre a chapa. As amostras foram embutidas, lixadas e por fim, polidas com pasta diamante, granulometria de $1 \mu \mathrm{m}$. Com solução de $45 \mathrm{~mL} \mathrm{HCl}, 15 \mathrm{~mL} \mathrm{HNO}_{3}$ e $20 \mathrm{~mL}$ de metanol, realizou-se o ataque metalográfico, e, em seguida, os corpos de prova foram analisados no microscópio óptico.

\section{Ensaio de Polarização Potenciodinâmica Anódica Linear}

Para realizar os ensaios, as amostras foram devidamente lixadas e embutidas em resina epóxi. As curvas de polarização anódica potenciodinâmicas foram obtidas com um potenciostato AUTOLAB® PGSTAT $302 \mathrm{~N}$, com software Nova 2.0®. Os ensaios foram realizados em solução de $\mathrm{NaCl} 35$ g. $\mathrm{L}^{-1}$ e temperatura ambiente. Inicialmente foram realizadas medidas de potencial de circuito aberto (OCP), medido em 2100 segundos, a fim de avaliar o tempo de estabilização do potencial eletroquímico do material no meio. Foram aplicados potenciais de -20 até $800 \mathrm{mV}$, a uma taxa de $0,167 \mathrm{mV} . \mathrm{s}^{-}{ }^{1}$. Foram realizados ensaios eletroquímicos com metal base e as juntas soldadas com os dois aportes térmicos, separadamente.

\section{RESULTADOS E DISCUSSÃO}

\section{Análise da Microestrutura}

De acordo com Gill et al. (1995), nas soldas dos aços inoxidáveis austeníticos a presença de uma certa quantidade mínima de ferrita delta é obrigatória para evitar a ocorrência de trincas a quente e a presença de altos ciclos térmicos em que o material é exposto tornam a microestrutura mais grosseira. É relatado também que, com o aumento da entrada de calor ocorre o aumento dos espaçamentos dos braços dendríticos da ferrita delta. Nota-se, a partir da Figura 1, que a fusão foi excessivamente profunda, ocorrendo excesso de penetração no corpo de prova com maior energia de soldagem. Apesar disso, os parâmetros escolhidos foram adequados, devido as soldas resultantes, de ambos os corpos de prova, não apresentarem porosidades ou trincas. 


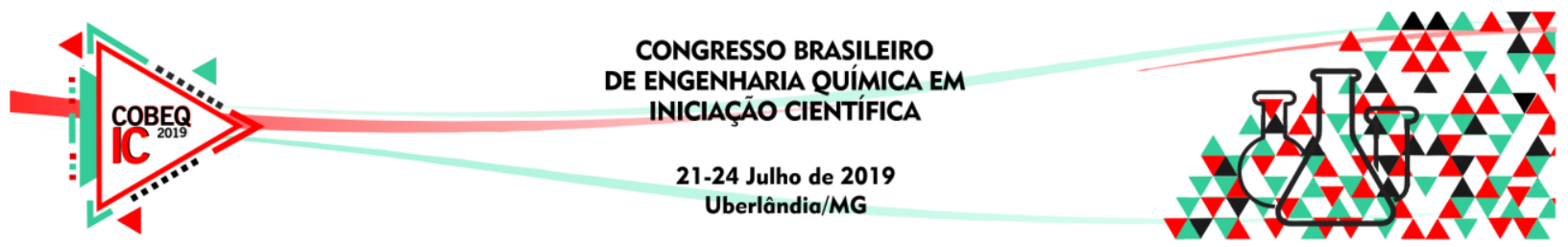

Figura 1 - Corpos de prova após o ataque metalográfico

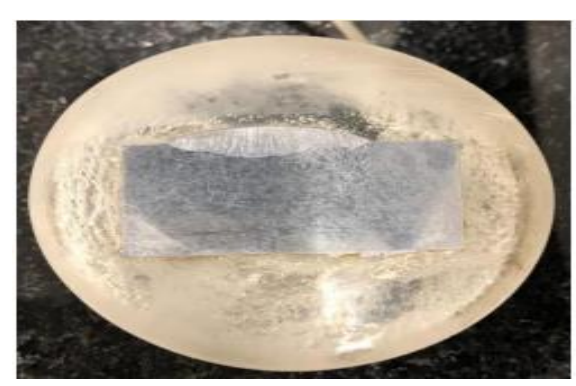

CP1 soldado com energia de $261 \mathrm{~kJ} . \mathrm{cm}^{-1}$

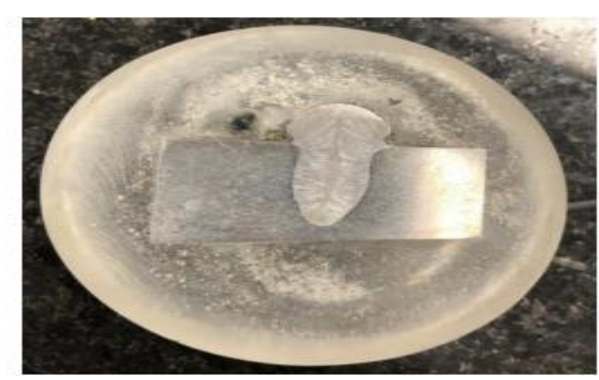

$\mathrm{CP}_{2}$ soldado com energia de $435 \mathrm{~kJ} . \mathrm{cm}^{-1}$

Após ataque metalográfico foram analisadas as microestruturas dos corpos de prova, com o auxílio do microscópio óptico. Observa-se que o material é composto por grãos poligonais de austenita e pequena quantidade de ferrita delta, conforme mostrado na Figura 2.

Figura 2 - Microscopia dos corpos de prova, com o aumento de 200x

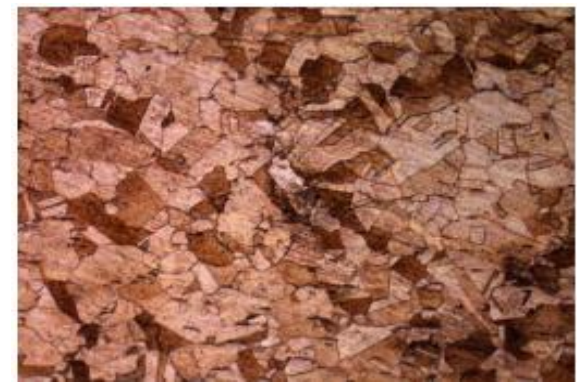

$\mathrm{CP}_{1}$ soldado com energia de $2,61 \mathrm{~kJ} \cdot \mathrm{mm}^{-1}$

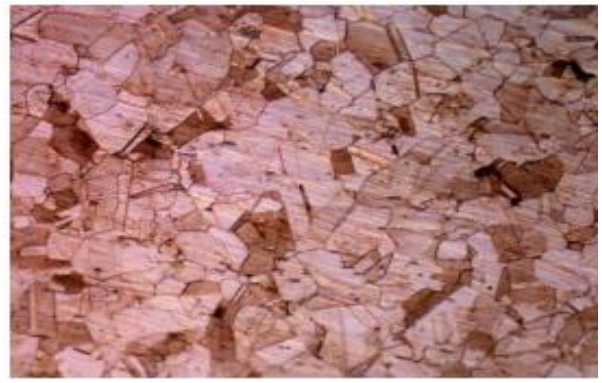

$\mathrm{CP}_{2}$ soldado com energia de $4,35 \mathrm{~kJ} \cdot \mathrm{mm}^{-1}$

\section{Ensaio de Polarização Potenciodinâmica Anódica Linear}

Na Figura 4 são apresentadas as curvas do potencial de circuito aberto,

Figura 4 - Curva de OCP para os três corpos de prova.

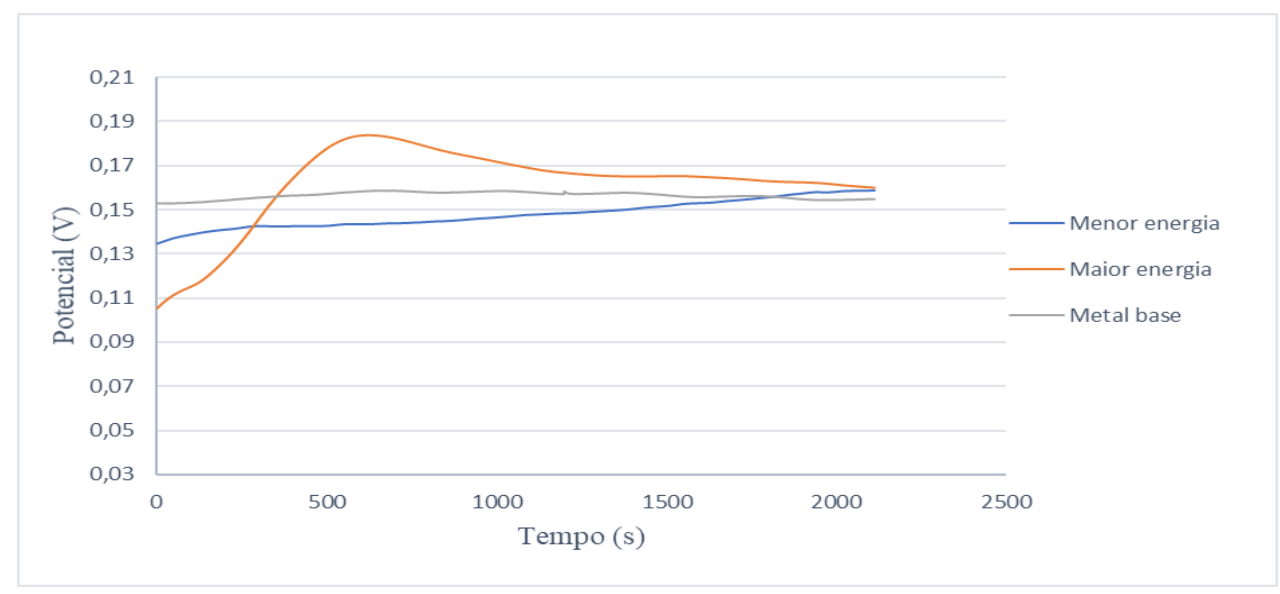




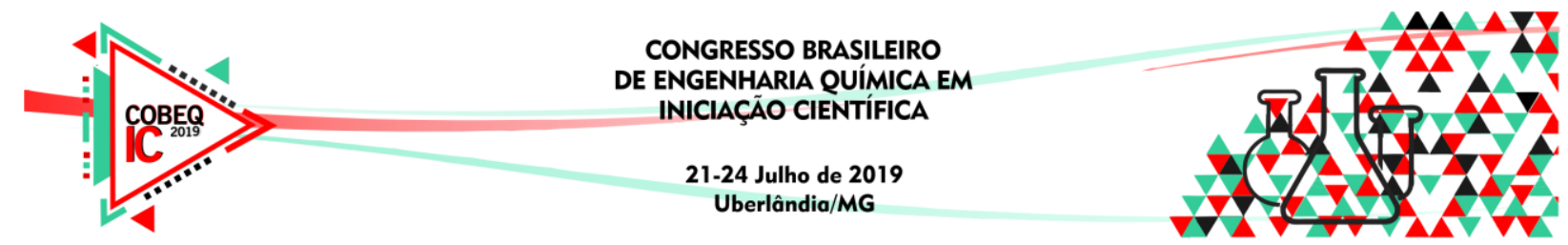

Ao analisar as curvas, pode-se concluir que o OCP dos três materiais foram semelhantes, se estabilizando em valores próximos de potencial e tempo, aproximadamente $0,16 \mathrm{~V}$ e 2100 segundos. Após atingida a estabilização do OCP, seguiu-se para o ensaio de polarização anódica potenciodinamica linear, e as curvas obtidas para as três amostras são mostradas na Figura 5.

Figura 5 - Curva de Polarização Linear para os três corpos de prova.

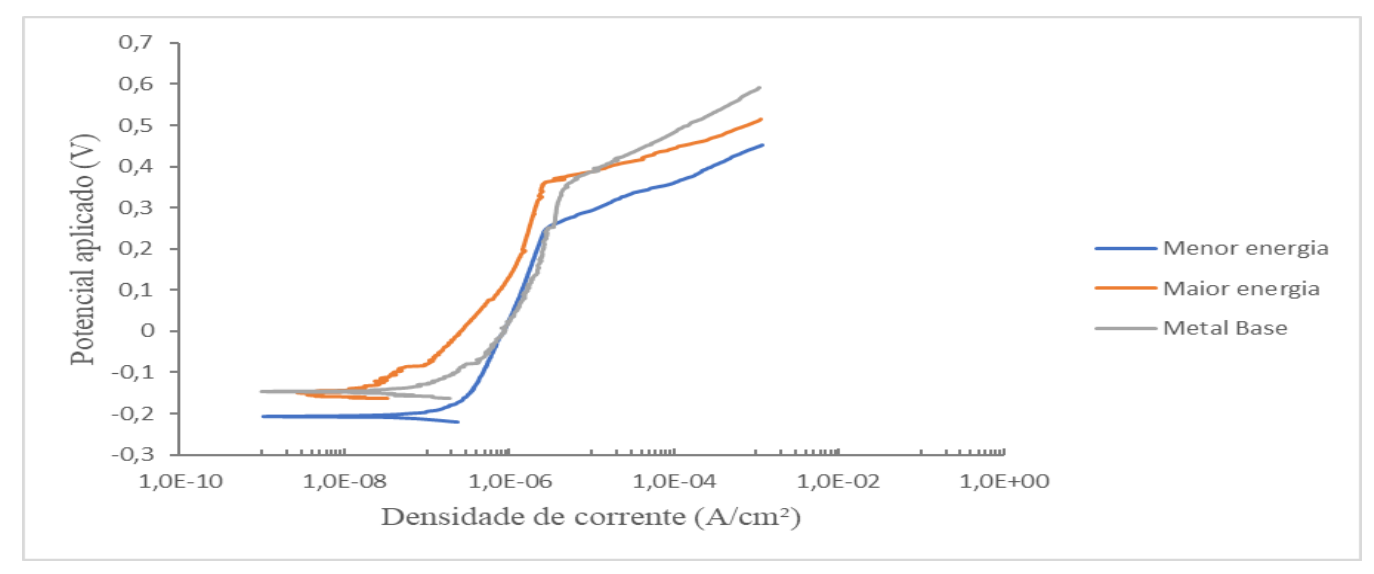

Pode-se observar que as curvas resultantes para os três corpos de prova tiveram o aspecto similar, quando expostos ao meio corrosivo. Através da análise do gráfico, conseguese obter parâmetros importantes para a avalição da susceptibilidade das amostras à corrosão por pites. Esses parâmetros são encontrados na Tabela 3.

Tabela 3 - Parâmetros encontrados pelo ensaio de polarização linear.

\begin{tabular}{|c|c|c|c|c|}
\hline Amostra & $\begin{array}{c}\text { Ecorrosão } \\
(\mathrm{mV})\end{array}$ & $\begin{array}{c}\text { Ipassivação } \\
\left(\mathrm{A} / \mathrm{cm}^{2}\right)\end{array}$ & $\begin{array}{c}\Delta \text { Epass } \\
(\mathrm{mV})\end{array}$ & $\begin{array}{c}\text { Epite } \\
(\mathrm{mV})\end{array}$ \\
\hline Metal Base & -146 & $1,8 \times 10^{-6}$ & 412 & 339 \\
\hline Solda - menor energia & -208 & $1,8 \times 10^{-6}$ & 404 & 233 \\
\hline Solda - maior energia & -146 & $8,7 \times 10^{-7}$ & 411 & 354 \\
\hline
\end{tabular}

Nos três ensaios foi possível observar a formação de uma camada protetora, a camada passiva, formada em densidades de corrente inferiores a $10^{-5} \mathrm{~A} \cdot \mathrm{cm}^{-2}$, indicando a formação de um filme com boa capacidade de proteção. A variação do potencial de passivação, $\Delta$ Epass, superior a $200 \mathrm{mV}$ indicando estabilidade da camada passiva, mostra, também, que o filme formado nos ensaios possui boa estabilidade.

O potencial de corrosão por pite, Epite, caracteriza o início da formação do pite. Quanto maior for o potencial de pite, mais resistente à formação do pite será o material. Verifica-se 


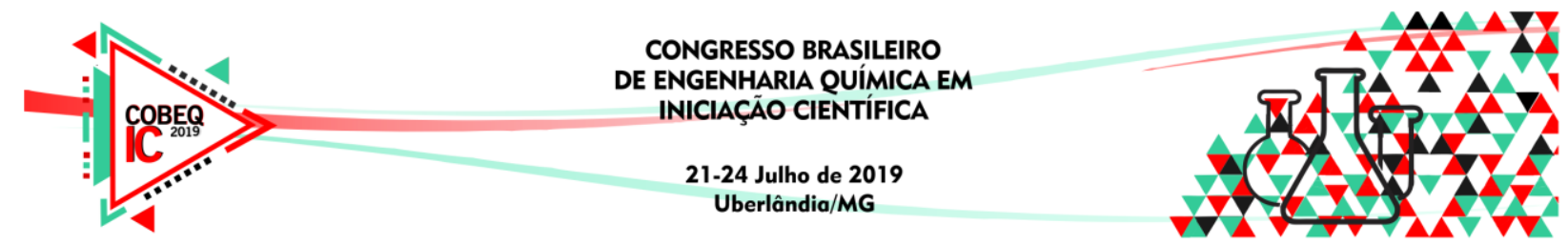

que os potenciais de pite foram semelhantes quando comparadas as curvas do metal base e da amostra com maior aporte térmico. Isto significa que as duas amostras possuem resistências similares à corrosão por pite. Porém, ocorreu uma diminuição no potencial de pite na solda com menor energia podendo indicar uma redução na resistência à corrosão por pites em relação às outras amostras. Contudo, faz-se necessário realizar os ensaios em triplicata a fim de avaliar com maior precisão os resultados.

Gill et al. (1995) relataram que a presença de ferrita delta em soldas austeníticas de aços com baixo teor de carbono pode levar a ataques preferenciais no metal em certos ambientes corrosivos. Os pites podem nuclear preferencialmente, dependendo da composição da liga, nas interfaces de austenita/ferrita delta ou dentro dos núcleos da austenita. A perda da resistência à corrosão por pite pode ser atribuída ao ataque preferencial de dendritas primárias na superfície da ferrita delta.

\section{CONCLUSÃO}

Os parâmetros de soldagem utilizados neste estudo foram apropriados, pois as soldas não apresentaram trincas e poros. Os corpos de prova estudados apresentaram boas características frente ao processo corrosivo, devido a formação de um filme protetor, compacto e estável, evidenciando a passivação destes no meio salino. Os valores dos parâmetros eletroquímicos, retirados da curva de polarização potenciodinâmica linear, mostraram similaridade, indicando que, o processo de soldagem não interferiu significativamente nas características de resistência à corrosão do material. Apesar deste fato, houve uma pequena redução no potencial de pite na solda com menor energia, sugerindo uma redução na resistência à corrosão por pites em relação às outras amostras. Esta tendência deve ser reavaliada com a realização de novos ensaios eletroquímicos.

\section{REFERÊNCIAS}

GILL, T.P.S; SHANKAR, V.; PUJAR, M.G.; RODRIGUEZ, P. Effect of composition on the transformation of -ferrite to in type 316 stainless steel weld metals. Scripta Metallurgica et Materialia, v32, n.10, p.1595-1600, 1995.

MARQUES, P.V; MODENESI, P.J; BRACARENSE, A. Q. Soldagem: Fundamentos $e$ Tecnologia. 3. ed., Belo Horizonte: UFMG, 2011.

NUNES, L. P. Fundamentos de resistência à corrosão. Rio de Janeiro: ABRACO, 2007.

PADILHA, A. F., GUEDES, L. C., Aços inoxidáveis austeníticos, microestrutura e propriedades. São Paulo: Hemus, 1994.

WAINER,E; BRANDI, S. D.; MELLO, F. D. H. Soldagem: Processos e Metalurgia. São Paulo: Edgard Blüncher Ltda, 2004. 